\title{
INFORMATION CONTENT OF TRANSACTION VOLUME: THE HOUSING MARKET IN THE UNITED KINGDOM
}

\author{
I-Chun TSAI ${ }^{1, *}$ \\ ${ }^{1}$ Department of Finance, National University of Kaohsiung, No. 700, Kaohsiung University Rd., \\ Nanzih District 811, Kaohsiung, Taiwan
}

Received 18 August 2016; accepted 4 October 2017

\begin{abstract}
According to search theory, transaction volume possesses the function of price discovery and reflects information more rapidly than price does. However, the findings of previous empirical studies differ considerably. In this study, a theoretical model is first established to analyze the potential information lag of transaction volume during pessimistic speculation. Data on the UK housing market are collected to conduct an empirical analysis of the responses of housing transaction volume to different market conditions. The results show that transaction volume responds to market information more quickly than does housing prices. However, under increasing market uncertainty, transaction volume lags four periods before reflecting the effect of the uncertainty. Moreover, this study performs a rolling window bootstrap Granger causality test, revealing that price leads volume during the period in which transaction volume fails to reflect an immediate rise in market uncertainty. An increase in market uncertainty reduces transaction volume. In addition, once transaction volume drops below a specific threshold, it loses its information content and price discovery function, extending the leadlag gap with housing prices by two periods. The present study proposes a simple method for determining the informativeness of housing transaction volume.
\end{abstract}

Keywords: price-volume relationship, Search theory, housing transaction volume, information content, price discovery.

\section{Introduction}

In contrast to the stock market, the price-volume relationship (PVR) of the housing market has yet to be fully explained. The "price-leads-volume" situation happens frequently in the stock market, whereas the opposite is true in the housing market. ${ }^{1}$ Therefore, price-volume models based on the features of housing market traders (e.g., search models) is essential to examining the particular situation of the housing market. Search Theory asserts that transaction volume reflects the information about the

\footnotetext{
1 Clark (1973), T. Epps and M. Epps (1976), and Copeland (1976) have mainly employed the perspectives of information flow or information asymmetry to discuss the lead-lag relationship between trading price and trading volume in the stock market. Karpoff (1987) compiles the relevant literature and emphasizes the importance of studying the price-volume relationship in a financial market. Gallant, Rossi, and Tauchen (1992) maintains that the emphasis should be placed on discussing the causal relationship between price and volume in a financial market to compare the efficiency of price and volume.
}

housing demand. Therefore, transaction volume contains the function of price discovery and can reflect information more rapidly than can price. However, using search models cannot piece together the puzzle of housing price versus transaction volume; that is, transaction volume informativeness may vary with market situations and time.

Although a high number of previous studies have confirmed that volume leads price in the housing market, numerous studies have also verified the lagging informativeness of transaction volume. For example, Miller and Sklarz (1986), who use several indicators of the Hawaiian housing market to examine the variables for predicting housing price trends, demonstrate the informativeness of transaction volume. Hort (2000) analyzes data from Sweden and reports that price is synchronously and negatively correlated to volume, and that transaction volume can reflect information more rapidly than can price. De Wit, Englund, and Francke (2013) show that volume-related variables more rapidly reflect interest rate shocks than do price-related variables. Shi, Young, and Hargreaves (2010) analyze the housing price and transaction volume trends

${ }^{\star}$ Corresponding author. E-mail: ictsai@nuk.edu.tw 
of 12 cities in New Zealand and conclude that in large cities, volume exhibits a significant lead over price. The aforementioned studies indicate that transaction volume is informative.

Stein (1995) proposes the down-payment model and explains that price leads transaction volume because a down payment is required for housing purchases. The said researcher analyzes US housing data, verifying that price data are more informative than volume data. Zhou (1997) also investigates the US housing market by employing a causality analysis, showing that price influences transaction volume. Genesove and Mayer (2001) examine data on downtown Boston in the 1990s and report that traders in the housing market are irrational. Specifically, they verify the disposition effect in the housing market and determine that loss aversion determines seller behavior in the housing market; accordingly, they conclude that housing price and transaction volume are significantly and positively correlated.

A number of researchers have identified varying PVRs in their empirical results. For example, Leung, Lau, and Leong (2002) examine the Hong Kong housing market and observe varying situations in which price leads volume, volume leads price, or no lead-lag relationship exists between the two variables. Andrew and Meen (2003) explore the housing price and transaction volume in Great Britain in the 1990s and reveal a structure change in the market, in which transaction volume decreases and cannot reflect housing prices. Clayton, Miller, and Peng (2010) analyze the housing markets in 114 metropolitan areas in the United States and observe that price and volume lead each other. However, the researchers also report that whereas decreasing housing price leads decreasing transaction volume, increasing housing price does not reflect increasing transaction volume.

The positive correlation between price and volume is predictable because both variables are associated with transaction behavior. The supply and demand of a market are likely to be affected by optimistic and pessimistic speculation. Under market equilibrium, price and volume also synchronously reach a balanced state. Subsequently, the emergence of specific restrictions in the market may cause one of the variables to change before the other. Tsai (2014) use a cobweb dynamic model to explain the convergence of price and volume in the housing market when negative speculation is present, and propose that according to the Walrasian and Marshallian equilibrium adjustment models, the order of the price and the volume adjustment may differ. The researcher examine the price-volume variables in the UK housing market between 1995 and 2012 and verify both price and volume lead each other during the research period; however, volume leads price more frequently.

Numerous studies have verified housing market prices to be less effective than other asset prices (Case \& Shiller, 1989, 1990; Clayton, 1998; Gu, 2002), which is consistent with the findings of previous studies, in which volume leads price more frequently. However, these studies have not fully explained why transaction volume becomes less informative occasionally and even lags behind housing prices during specific periods.

Comprehensive research investigating situations that affect the informativeness of transaction volume is imperative. On the basis of previous theoretical research, we propose a simple integrated model that accounts for buyer and seller behaviors, loss aversion, and down payment restriction to validate that the informativeness of transaction volume only becomes inadequate when pessimistic speculation is present in the housing market, leading to a decrease in transaction volume. The proposed empirical model not only validates the hypotheses formulated in the present study, but also provides evidence to support the argument that transaction volume size is a simple indicator for determining the informativeness of transaction volume. When buyer/seller behaviors are unrestricted in the housing market, changes are unlikely to occur in transaction volume regardless of the presence of optimistic or pessimistic speculations. By contrast, a decline in transaction volume is anticipated when the behavior of either the buyer or seller are restricted. Therefore, an exponential decline in transaction volume can be associated with how loss aversion or down payment restriction limits buyer/seller behaviors and hinders transactions. Under this situation, transaction volume becomes less informative.

The subsequent sections are organized as follows: Section 1 introduces the theoretical framework for explaining how the informativeness of transaction volume varies with market conditions; Section 2 discusses the research methods; Section 3 details the sample collection and empirical results; and the last section concludes this study.

\section{Theoretical model}

In this section, we describe the simple model adopted to explain the expected changes of transaction volume in the housing market. The market is assumed to comprise $N$ assets, where the buyer reservation price for the $i^{\text {th }}$ asset is the highest price a buyer is willing to pay $\left(P_{i, b}\right)$, and the seller reservation price for the $i^{\text {th }}$ asset denotes the lowest price a seller is willing to accept $\left(P_{i, s}\right)$.

A transaction only occurs when $P_{i, b} \geq P_{i, s}$. The transaction price is expressed as $p_{t}=\frac{P_{i, b}+P_{i, s}}{2}$.

Subsequently, $m_{b}$ and $m_{s}$ represents the numbers buyers and sellers in the market, respectively. The successful transaction of a buyer or seller depends on the price. Therefore, the most competitive prices are the highest buying price and the lowest selling price, which can be expressed as follows:

$$
\begin{aligned}
& P_{i, b}^{\max }=\max \left\{P_{i, b}^{1}, \ldots, P_{i, b}^{m_{b}}\right\}, \\
& P_{i, s}^{\min }=\min \left\{P_{i, s}^{1}, \ldots, P_{i, s}^{m_{s}}\right\} .
\end{aligned}
$$


Let $S_{i, t}=\left(P_{i, b, t}^{\max }-P_{i, s, t}^{\min }\right)$, or the bid-ask spread in the $t^{\text {th }}$ period. Therefore, the transaction probability of the $i^{\text {th }}$ asset in the $t^{\text {th }}$ period can be expressed as follows:

$\pi_{t}=\operatorname{Prob}\left(S_{i, t} \geq 0\right)$.

The expected transaction volume in the market in the $t^{\text {th }}$ period can be expressed as follows:

$$
E\left(V_{t}\right)=E\left(\sum_{i=1}^{N} \pi_{t} \times 1\right)
$$

Assuming that the traders are rational, $\Omega_{t}$ represents the data set in the $t^{\text {th }}$ period. Using this data, traders adjust their intrinsic value of the $i^{\text {th }}$ asset $\left(\tilde{P}_{i, v}\right)$. That is, the bid (ask) price of the $j^{\text {th }}$ buyer (seller) is based on $E_{j}\left(\tilde{P}_{i, v} \mid \Omega_{t}\right)$, where $\mathrm{j}=1, \ldots, m_{b}\left(m_{s}\right)$.

$P_{i, b, t}^{\max }, P_{i, s, t}^{\min }, S_{i, t}$, and $\pi_{t}$ are all functions of $\Omega_{t}$. Therefore, $p_{t}$ and $V_{t}$ are also functions of $\Omega_{t}$. In the following section, we discuss the changes in transaction volume for different market conditions (i.e., optimistic and pessimistic speculations).

\section{(1) Optimistic speculation}

We assume that optimistic speculation is present in the housing market in the $t^{\text {th }}$ period. Without accounting for information asymmetry, optimistic speculation affects the buyers and sellers in the market similarly.

$$
E_{j}\left(\tilde{P}_{i, v} \mid \Omega_{t}\right)=E_{j}\left(\tilde{P}_{i, v} \mid \Omega_{t-1}\right)+\beta_{i, t},
$$

where: $\beta_{i, t}$ represents the appreciation of the $i^{\text {th }}$ asset as a result of optimistic speculation.

$$
\begin{aligned}
& E\left(S_{i, t}\right)=E\left(P_{i, b, t}^{\max }-P_{i, s, t}^{\min }\right)=E\left[\left(P_{i, b, t-1}^{\max }+\varepsilon_{i, t}\right)-\left(P_{i, s, t-1}^{\min }+\right.\right. \\
& \left.\left.\varepsilon_{i, t}\right)\right]=E\left(P_{i, b, t-1}^{\max }-P_{i, s, t-1}\right) .
\end{aligned}
$$

The expected spread remains unchanged. The probability of an expected spread value $>0$ also remains unchanged. Therefore, no expected changes in the housing transaction volume occur. Only the expected transaction price increases by $\beta_{i, t}$.

$$
E\left(V_{t}-V_{t-1}\right)=0 .
$$

\section{(2) Pessimistic speculation}

We assume that pessimistic speculation is present in the housing market in the $t^{\text {th }}$ period. Without accounting for information asymmetry, pessimistic speculation affects the buyers and sellers in the market similarly.

$$
E_{j}\left(\tilde{P}_{i, v} \mid \Omega_{t}\right)=E_{j}\left(\tilde{P}_{i, v} \mid \Omega_{t-1}\right)-\beta_{i, t} .
$$

In addition, no changes in transaction volume are expected when traders are rational and financing is unrestricted.

$$
\begin{aligned}
& E\left(S_{i, t}\right)=E\left(P_{i, b, t}^{\max }-P_{i, s, t}^{\min }\right)=E\left[\left(P_{i, b, t-1}^{\max }-\beta_{i, t}\right)-\left(P_{i, s, t-1}^{\min }-\right.\right. \\
& \left.\left.\beta_{i, t}\right)\right]=E\left(P_{i, b, t-1}^{\max }-P_{i, s, t-1}^{\min }\right) ; \\
& E\left(V_{t}-V_{t-1}\right)=0 .
\end{aligned}
$$

Two types of restrictions are considered, namely, the disposition effect (Genesove \& Mayer, 2001) and the down payment restriction (Stein, 1995). (i) Situation 1: Sellers' asking price is restricted when the disposition effect is present.

We assume that the $j^{\text {th }}$ seller rejects prices lower than $\bar{P}_{i, s}^{j}$. Therefore, the function of the most competitive asking price with the aforementioned restriction can be expressed as follows:

$$
\bar{P}_{i, s}^{\min }=\min \left[\max \left(P_{i, s}^{1}, \bar{P}_{i, s}^{1}\right), \ldots, \max \left(P_{i, s}^{m_{s}}, \bar{P}_{i, s}^{m_{s}}\right)\right] .
$$

The expected bid-ask spread affected by the disposition effect $\left(E\left(S_{i, t}\right)_{\text {loss }}\right)$ can be expressed as follows:

$$
E\left(S_{i, t}\right)_{\text {loss }}=E\left(P_{i, b, t}^{\max }-\bar{P}_{i, s}^{\min }\right) \leq E\left(P_{i, b, t}^{\max }-P_{i, s, t}^{\min }\right)=E\left(S_{i, t}\right) .
$$

Under the disposition effect, the expected market transaction volume in the $t^{\text {th }}$ period is $E\left(V_{t}\right)_{\text {loss }}$.

$$
E\left(V_{t}\right)_{\text {loss }}=\sum_{i=1}^{N} E\left(\pi_{t}\right)_{\text {loss }} \leq \sum_{i=1}^{N} E\left(\pi_{t}\right)=E\left(V_{t}\right) .
$$

Thus, expected transaction volume decreases when the disposition effect is present. Transaction volume is affected by sellers' price restriction $\left(\bar{P}_{i, s}^{j}\right)$. Disposition effect theory explains that this restriction originates from sellers' previous transactions; hence, the price might lag by $\lambda$ period, or $p_{t-\lambda}\left(\Omega_{t-\lambda}\right)$. Accordingly, the transaction volume is affected by $\Omega_{t-\lambda}$, leading to information lag.

(ii) Situation 2: Buyers' bidding price is restricted when their financing is obstructed; that is, when the down payment restriction is present.

We assume that the $j^{\text {th }}$ buyer is unable to pay a price higher than $\bar{P}_{i, b}^{j}$ because of inadequate funds. Therefore, the function of the most competitive bidding price can be expressed as follows:

$$
\bar{P}_{i, b}^{\max }=\max \left[\min \left(P_{i, b}^{1}, \bar{P}_{i, b}^{1}\right), \ldots, \min \left(P_{i, b}^{m_{b}}, \bar{P}_{i, b}^{m_{b}}\right)\right] .
$$

The expected bid-ask spread affected by the down payment restriction $\left(E\left(S_{i, t}\right)_{\text {down }}\right)$ can be expressed as follows:

$$
\begin{aligned}
& E\left(S_{i, t}\right)_{\text {down }}=E\left(\bar{P}_{i, b, t}^{\max }-P_{i, s, t}^{\min }\right) \leq E\left(P_{i, b, t}^{\max }-P_{i, s, t}^{\min }\right)= \\
& E\left(S_{i, t}\right) .
\end{aligned}
$$

Under the down payment restriction, the expected market transaction in the $t^{\text {th }}$ period is $E\left(V_{t}\right)_{\text {down }}$.

$$
E\left(V_{t}\right)_{\text {down }}=\sum_{i=1}^{N} E\left(\pi_{t}\right)_{\text {down }} \leq \sum_{i=1}^{N} E\left(\pi_{t}\right)=E\left(V_{t}\right) .
$$

Thus, expected transaction volume decreases when the down payment restriction is present. Transaction volume is affected by buyers' price restriction $\left(\bar{P}_{i, b}^{j}\right)$. Down payment theory explains that this restriction originates from buyers' other housing prices. Hence, the housing price lags by $\lambda$ periods, or $p_{t-\lambda}\left(\Omega_{t-\lambda}\right)$. Accordingly, the transaction volume is affected by $\Omega_{t-\lambda}$, leading to information lag.

According to Situation 1 and Situation 2, we infer that both the disposition effect and down payment restriction affect trader behaviors, reduce transaction volume, and cause information lag. 


\section{Empirical methodology}

We infer that the PVR in the housing market is affected by market conditions, particularly when trader behaviors are affected by pessimistic speculation. First, a bivariate vector autoregressive (VAR) model is developed with $y$ as housing price and $x$ as transaction volume:

$\left[\begin{array}{l}\Delta \ln y_{t} \\ \Delta \ln x_{t}\end{array}\right]=\left[\begin{array}{l}a_{10} \\ a_{20}\end{array}\right]+\left[\begin{array}{ll}a_{11}(L) & a_{12}(L) \\ a_{21}(L) & a_{22}(L)\end{array}\right]\left[\begin{array}{l}\Delta \ln y_{t} \\ \Delta \ln x_{t}\end{array}\right]+\left[\begin{array}{c}\varepsilon_{1 t} \\ \varepsilon_{2 t}\end{array}\right],(17)$

where: $a_{i j}(L)=\sum_{c=1}^{p+1} a_{i j, c} L^{c} ; i, j=1,2$ and $L$ is the lag opera-
tor.

According to (17), a null hypothesis is formulated to verify that housing price return cannot Granger-cause transaction volume variation, which can be expressed as follows:

$$
H_{0}: a_{12,1}=a_{12,2}=\ldots=a_{12, p}=0 \text {. }
$$

Another null hypothesis is proposed to verify that transaction volume variation cannot Granger-cause housing price return:

$$
H_{0}: a_{21,1}=a_{21,2}=\ldots=a_{21, p}=0 .
$$

Regarding assets investment behaviors, risk (or uncertainty) is a typical factor of negative influence. Specifically for real estate investment that involves a large amount of money and a long mortgage period, when uncertainty exists on the market, the risk increases substantially. In this case, people tend to stay put and wait and are less likely to have active trading behaviors. Therefore, increased uncertainty in policies can be viewed as a negative factor that enhances market risks. Policy certainty is extremely crucial to traders in all asset markets because it is positively correlated with the risk assumed by the traders.

An increasing number of empirical studies have verified that economic policy uncertainty (EPU) negatively affects asset prices. For example, Bansal and Yaron (2004) develop an asset pricing model to explain the negative influence of economic uncertainty on asset prices. Dzielinski (2011), Bijsterbosch and Guérin (2013), and Ko and Lee (2015) have verified that a rise in EPU negatively influences the stock market, markedly decreasing the stock prices. Hoshi (2011) mentions that EPU might expedite the deterioration of the financial environment. Kang and Ratti (2013) report that a rise in policy uncertainty negatively influence the automobile and retail industries in the short term and gold-related stock prices in the long term. Aastveit et al. (2013) provide evidence to show that a rise in uncertainty dampens the effectiveness of monetary policies. The preceding studies collectively indicate that EPU has a negative impact on the overall economy and promotes pessimistic speculation in asset markets, hence EPU is adopted as a proxy variable for pessimistic speculation in this paper. We incorporate the UK EPU Index to account for the pessimistic speculation in the market. This index is established by Baker, Bloom, and Davis (2016) and based on newspaper coverage frequency. Specifically, an elevated EPU index value represents a higher level of policy uncertainty and more prominent pessimistic speculation in the market.
Therefore, we incorporate EPU into (17) to determine whether pessimistic speculation in the market influences price and volume.

$$
\begin{aligned}
& {\left[\begin{array}{l}
\Delta \ln y_{t} \\
\Delta \ln x_{t}
\end{array}\right]=\left[\begin{array}{l}
a_{10} \\
a_{20}
\end{array}\right]+\left[\begin{array}{ll}
a_{11}(L) & a_{12}(L) \\
a_{21}(L) & a_{22}(L)
\end{array}\right]+\left[\begin{array}{l}
\Delta \ln y_{t} \\
\Delta \ln x_{t}
\end{array}\right]+} \\
& {\left[\begin{array}{ll}
b_{11}(L) & b_{22}(L)
\end{array}\right]\left[E P U_{t}\right]+\left[\begin{array}{l}
\varepsilon_{1 t} \\
\varepsilon_{2 t}
\end{array}\right] .}
\end{aligned}
$$

In addition, we address how the sudden emergence of the two pessimistic speculation situations discussed in Section 1 affects the market. The dynamic causality must be observed to determine the changes in transaction volume informativeness over time. Therefore, we adopt the bootstrap rolling window estimation to test causality. The bootstrap method was introduced by Bradley Eforn in 1979. Later, Mantalos (2000) and Mantalos and Shukur (1998) applied the bootstrap method to causality tests, verifying that the method produce more accurate and stable results.

\section{Data and empirical results}

The data analyzed in the present study are the housing price indices (HPI) and the transaction volume data contained in the UK Land Registry Open Data. The UK EPU Index established by Baker et al. (2016) is used to account for the pessimistic speculation in the market. The time period used in this paper is from January 2005 to March 2016. During empirical estimation, the natural logarithms of all datasets are calculated.

Table 1 displays the simple statistics of the data and the

\begin{tabular}{|c|c|c|c|}
\hline Statistics & $H P I$ & $V$ & $E P U$ \\
\hline Mean & 91.5547 & 82414.50 & 175.3117 \\
\hline Median & 89.6100 & 76306 & 163.1825 \\
\hline Maximum & 108.7200 & 139459 & 479.3260 \\
\hline Minimum & 78.9300 & 30507 & 30.4688 \\
\hline Std. Dev. & 6.9319 & 25277.01 & 90.5887 \\
\hline Skewness & 0.5975 & 0.3273 & 0.6432 \\
\hline Kurtosis & 2.7383 & 2.3420 & 3.1636 \\
\hline \multicolumn{4}{|c|}{ ADF unit root test } \\
\hline Original data & $\begin{array}{c}1.0731 \\
(0.9256) \\
\end{array}$ & $\begin{array}{c}-0.0004 \\
(0.6806) \\
\end{array}$ & $\begin{array}{c}0.6261 \\
(0.8504) \\
\end{array}$ \\
\hline Differenced & $\begin{array}{l}-2.7405 \\
(0.0064)\end{array}$ & $\begin{array}{l}-2.1088 \\
(0.0341)\end{array}$ & $\begin{array}{r}-16.7277 \\
(0.0000)\end{array}$ \\
\hline \multicolumn{4}{|c|}{ PP unit root test } \\
\hline Original data & $\begin{array}{c}1.5006 \\
(0.9668) \\
\end{array}$ & $\begin{array}{c}0.3863 \\
(0.7941) \\
\end{array}$ & $\begin{array}{c}0.9086 \\
(0.9022) \\
\end{array}$ \\
\hline Differenced & $\begin{array}{l}-4.9423 \\
(0.0000)\end{array}$ & $\begin{array}{c}-12.7840 \\
(0.0000)\end{array}$ & $\begin{array}{c}-18.0544 \\
(0.0000)\end{array}$ \\
\hline
\end{tabular}
unit root test results, showing that the fluctuation of housing prices is markedly smaller than that of transaction

Table 1. Basic statistics and unit root tests

Notes: HPI denotes housing price index, $V$ denotes trading volume, and $E P U$ denotes Economic policy uncertainty. ADF and PP tests are adopted for testing the null hypothesis of a unit root in the series. The intercept and trend are excluded in the testing equation, and the lag length of the unit root models is selected by using the Schwarz information criterion. The entry in parenthesis stands for the $p$-value. 
volume. The average HPI is 91.55 , with a margin of 30 between the highest and lowest values. The average transaction volume is 82,414 , with a margin of 108,952 between the highest and lowest values. This indicates that the variation of transaction volume is far greater than that of housing prices. EPU also exhibited a large margin of fluctuation, with a mean value was 175 . The lowest EPU
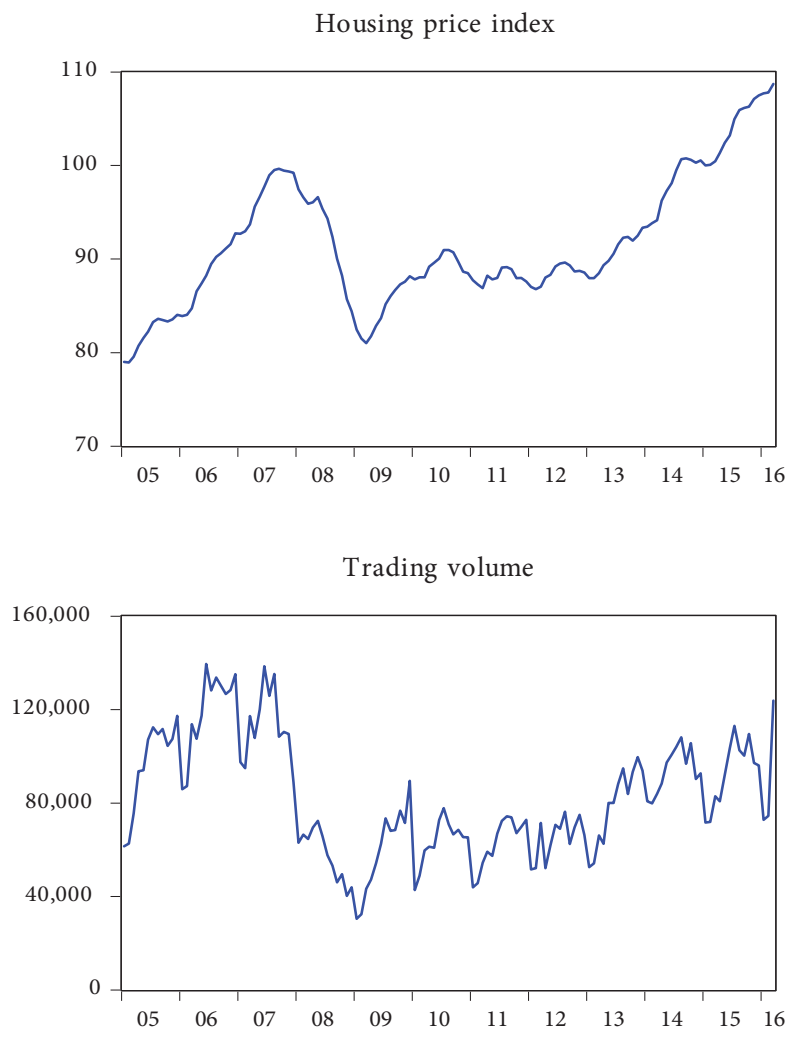

EPU

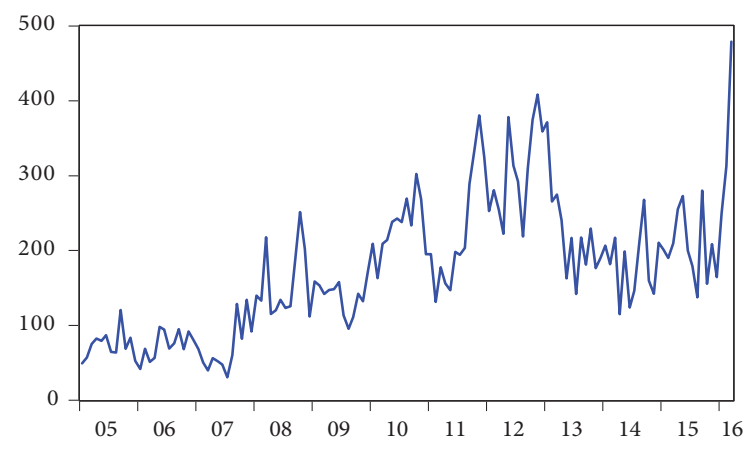

Figure 1. Time series of variables value, which denotes the most stable state of the market, is 30 . The value increases exponentially to 400 as market uncertainty increases.

Figure 1 illustrates the housing price, transaction volume, and EPU trends. The results reveal that the largest correction in both housing prices and volume occurred in 2008. However, transaction volume began to correct downward drastically during the second half of 2007, reaching the lowest point in 2008. Apart from the stagnation in housing prices between 2011 and 2012 as a result of the European debt crisis, both price and volume exhibited a gradual recovery following 2009. In particular, housing prices rose exponentially from 2015 to 2016. Fluctuation in the EPU Index values reveals that the overall economy was unstable following 2008. Market uncertainty rose between 2011 and 2013 as a result of the European debt crisis and peaked at the beginning of 2016 with the occurrence of the United Kingdom European Union membership referendum.

In addition to descriptive statistics, the results of the stationarity test, or the unit root test, are also displayed in Table 1 . The test results indicate that housing prices, transaction volume, and EPU are integrated of order 1 (I(1)). Specifically, analyzing the original data of housing price, transaction volume, and EPU shows that they are all nonstationary. However, examining the first order differential data of the variables reveals that they are stationary. Because the original data of housing prices and transaction volume are I(1), we first use a cointegrated relationship method to estimate whether a long-run equilibrium relationship is present between housing prices and transaction volume, thereby comprehensively addressing the patterns of housing prices and transaction volume.

Table 2 lists the cointegration test results obtained using the maximum likelihood estimation method proposed by Johansen $(1988,1991)$ and Johansen and Juselius (1990). The estimation results produced using the trace test and max-eigen test are separately tabulated in Table 2. The results of both tests reject the null hypothesis that no long-run integrated relationships exist between housing prices and transaction volume, verifying the presence of a long-term cointegrated relationship between housing prices and transaction volume. Engle and Granger (1987) suggest when a long-run integrated relationship exists between two variables, they also attain a causal relationship in short run. Therefore, we adopt the vector error correction model (VECM) to estimate the mutual adjustments of housing prices and transaction volume.

Table 2. Cointegration test

\begin{tabular}{|c|c|c|c|c|}
\hline Hypothesized No. of CE(s) & Eigenvalue & Trace Statistic & 0.05 Critical Value & $p$-value \\
\hline None & 0.1740 & 28.4114 & 15.4947 & 0.0003 \\
\hline At most 1 & 0.0270 & 3.5609 & 3.8415 & 0.0592 \\
\hline Hypothesized No. of CE(s) & Eigenvalue & Max-Eigen Statistic & 0.05 Critical Value & $p$-value \\
\hline None & 0.1740 & 24.8505 & 14.2646 & 0.0008 \\
\hline At most 1 & 0.0270 & 3.5609 & 3.8415 & 0.0592 \\
\hline
\end{tabular}

Notes: This table shows the results of testing the cointegration relationship between housing price index and trading volume.

$\mathrm{CE}$ denotes cointegrating equation. 
Table 3. Vector error correction estimates

\begin{tabular}{|l|c|c|}
\hline \multicolumn{1}{|c|}{ Variables } & $\Delta \ln H P I$ & $\Delta \ln V$ \\
\hline$Z_{t-1}$ & -0.0009 & $-0.1063^{\star * *}$ \\
& {$[-0.9133]$} & {$[-4.9345]$} \\
\hline$\Delta \ln H P I_{t-1}$ & $0.4527^{\star * *}$ & $5.8096^{\star * *}$ \\
& {$[4.4113]$} & {$[2.5931]$} \\
\hline$\Delta \ln H P I_{t-2}$ & $0.2556^{* * *}$ & $5.0832^{* *}$ \\
& {$[2.6827]$} & {$[2.4438]$} \\
\hline$\Delta \ln V_{t-1}$ & $0.0142^{\star * *}$ & $-0.2185^{\star *}$ \\
& {$[3.2195]$} & {$[-2.2764]$} \\
\hline$\Delta \ln V_{t-2}$ & 0.0012 & $-0.3031^{\star * *}$ \\
& {$[0.2651]$} & {$[-3.1909]$} \\
\hline Constant & 0.0007 & -0.0212 \\
& {$[1.0938]$} & {$[-1.5792]$} \\
\hline
\end{tabular}

Notes: $\triangle \ln H P I$ is the growth rate of housing price index, $\Delta \ln V$ is the growth rate of trading volume. $Z$ is the error term of the cointegrating equation. The cointegrating equation is $\Delta \ln H P I_{t}+2.31 \ln V_{t}-30.50$. Entry in parenthesis stands for the $t$ statistics. The optimal lag length of the estimated model was chosen by the Schwarz information criterion. ${ }^{* * *}$ indicates significance at the $1 \%$ level. ${ }^{* *}$ indicates significance at the $5 \%$ level.

Table 3 illustrates the estimation results produced through the VECM. The error correction coefficient $\left(Z_{t-1}\right)$ of the previous period shows a long-run cointegrated relationship in which transaction volume corrects toward housing prices. When the dependent variable is housing price return $(\Delta \ln H P I)$, the error correction coefficient is nonsignificant. However, when the dependent variable is transaction volume variation $(\Delta \ln V)$, the error correction coefficient is significant to be -0.1063 , implying that transaction volume is corrected when it shifts away from its long-run equilibrium with housing price. An error correction coefficient value $<0$ indicates that transaction volume is higher than that in the long-run equilibrium and requires downward correction; hence, the variation of transaction volume decreases.

In the short term, housing price return exhibits a positive autocorrelation and a positive correlation with transaction volume variation in the previous period. Transaction volume demonstrates a negative autocorrelation and a positive correlation with housing price return lagging by two periods. Table 3 shows that in the long term, transaction volume is corrected toward housing prices, whereas in the short term, volume and price leads and lags each other.

Table 4 lists the results of a short-run causality test between housing prices and transaction volume. However, the exclusion of long-run integration factors leads to an underestimation of the effects of housing prices on transaction volume. The housing price return significantly lags behind

Table 4. Pairwise Granger causality tests

\begin{tabular}{|c|c|c|}
\hline Null hypothesis & $F$-Statistic & $p$-value \\
\hline$\Delta \ln V$ does not Granger cause $\Delta \ln H P I$ & 5.2850 & 0.0062 \\
\hline$\Delta \ln H P I$ does not Granger cause $\Delta \ln V$ & 2.6382 & 0.0754 \\
\hline
\end{tabular}

Notes: $\triangle \ln H P I$ is the growth rate of housing price index, $\Delta \ln V$ is the growth rate of trading volume. transaction volume variation. Therefore, transaction volume possesses the price discovery function. By contrast, the housing price return was less informative and shows no significant lead when compared to transaction volume variation.

The results in Table 4 are largely consistent with those of previous studies, in which volume substantially leads price. However, these results may underestimate the informativeness of housing prices and overestimate that of transaction volume. By using the proposed theoretical model, we infer that when pessimistic speculation occurs in the market, housing transactions may be restricted, reducing the informativeness of transaction volume. Therefore, we incorporate EPU variation as an explanatory variable to account for the rise in market uncertainty (Table 5). The results show that housing price return is not affected by a rise in uncertainty, but transaction volume variation exhibits a significant autocorrelation and is positively affected by lagging housing price return and EPU variation. When the EPU that lags four periods increases, the transaction volume decrease, indicating that the negative speculation occurring four periods ago affects the transaction volume of the current period; this causes the transaction volume to contract. The results of Table 5 indicate that the responses of transaction volume to EPU information are much slower than those of housing prices, suggesting that transaction

Table 5. VECM including EPU effect

\begin{tabular}{|l|c|c|}
\hline \multicolumn{1}{|c|}{ Variables } & $\Delta \ln H P I$ & $\Delta \ln V$ \\
\hline$Z_{t-1}$ & -0.0006 & $-0.0995^{* * *}$ \\
& {$[-0.5852]$} & {$[-4.8443]$} \\
\hline$\Delta \ln H P I_{t-1}$ & $0.4353^{\star * *}$ & $6.5068^{\star * *}$ \\
& {$[4.0568]$} & {$[2.8636]$} \\
\hline$\Delta \ln H P I_{t-2}$ & $0.2434^{* *}$ & $4.4755^{* *}$ \\
& {$[2.4559]$} & {$[2.1325]$} \\
\hline$\Delta \ln V_{t-1}$ & 0.0139 & $-0.2474^{* * *}$ \\
& {$[3.1248]^{* * *}$} & {$[-2.6243]$} \\
\hline$\Delta \ln V_{t-2}$ & 0.0013 & $-0.3108^{* * *}$ \\
& {$[0.2953]$} & {$[-3.3128]$} \\
\hline $\operatorname{Constant}^{* *}$ & 0.0008 & -0.0235 \\
& {$[1.2010]$} & {$[-1.7491]$} \\
\hline$\Delta E P U_{t-1}$ & -0.0006 & 0.0673 \\
& {$[-0.2531]$} & {$[1.4494]$} \\
\hline$\Delta E P U_{t-2}$ & -0.0014 & 0.0581 \\
& {$[-0.6037]$} & {$[1.1598]$} \\
\hline$\Delta E P U_{t-3}$ & -0.0014 & 0.0015 \\
& {$[-0.6070]$} & {$[0.0299]$} \\
\hline$\Delta E P U_{t-4}$ & -0.0035 & $-0.1025^{* *}$ \\
& {$[-1.6381]$} & {$[-2.2489]$} \\
\hline
\end{tabular}

Notes: $\triangle \ln H P I$ is the growth rate of housing price index, $\Delta \ln V$ is the growth rate of trading volume. $Z$ is the error term of the cointegrating equation. The cointegrating equation is $\Delta \ln H P I_{t}+2.31 \ln V_{t}-30.50$. $\triangle E P U$ denotes the growth rate of economic policy uncertainty. Entry in parenthesis stands for the $t$ statistics. The optimal lag length of the estimated model was chosen by the Schwarz information criterion. ${ }^{* * *}$ indicates significanceat the $1 \%$ level. ${ }^{* *}$ indicates significance at the $5 \%$ level. 
volume decreases during the drastic changes in EPU, reducing the informativeness of transaction volume.

To verify the influence of pessimistic speculation on the information content of transaction volume, we examine the dynamic transaction volume data by using the rolling window bootstrap Granger causality test (Table 6). The results reveal both leading and lagging relationships between housing prices and transaction volume. Only transaction volume lags behind EPU because EPU variation significantly Granger-causes transaction volume variation. A rolling window of 36 months is adopted to test causality. ${ }^{2}$ The changes in causality over time ( $p$ value) are illustrated in Figures 2 and 3. The $p$-value is used to determine whether a significant causal relationship is present in the estimation period. Each estimation result ( $p$ value) is obtained using data from each 36 -month period. Similar to previous studies, the horizontal axis of the graph is plotted using the midpoint of each 36-month period. For example, the $p$ value of June 2006 corresponds to the estimated result obtained the data spanning January 2015 to December 2017. In addition, a standard line of $p=0.1$ is displayed in Figures 2 and 3 to distinguish the periods with a significant causal relationship.

Table 6. Bootstrap Granger causality test

\begin{tabular}{|l|c|c|}
\hline \multicolumn{1}{|c|}{ Null hypothesis } & $F$-Statistic & $p$-value \\
\hline$\triangle \ln V$ does not Granger cause $\triangle \ln H P I$ & 10.2183 & 0.0000 \\
\hline$\triangle \ln H P I$ does not Granger cause $\Delta \ln V$ & 2.5523 & 0.0450 \\
\hline$\triangle E P U$ does not Granger cause $\Delta \ln H P I$ & 0.7157 & 0.5801 \\
\hline$\triangle E P U$ does not Granger cause $\Delta \ln V$ & 2.6869 & 0.0328 \\
\hline
\end{tabular}

Notes: $\triangle \ln H P I$ is the growth rate of housing price index, $\Delta \ln V$ is the growth rate of trading volume. $\triangle E P U$ denotes the growth rate of economic policy uncertainty.

Figure 2 illustrates the effects of uncertainty on housing price return and transaction volume variation, showing that the increase in uncertainty exerts a greater effect on transaction volume variation than on housing price return. Generally, the solid line in Figure 2 shows that the rise in uncertainty nonsignificantly Granger-causes housing price return (>0.05), except for May 2012, during which housing price return lags behind pessimistic speculation in the market. The dotted line in Figure 2 shows that the Granger causality of the rise in uncertainty on transaction volume is similar to that represented by the solid line. However, most of the significance levels are slightly lower than those indicated bythe solid line, suggesting that the lagging response of transaction volume to pessimistic speculation is more noticeable. During 2008, 2011-2012, and 2013, transaction volume exhibits lagging responses. These periods corresponds to times of financial instability and crisis, such as the rise in the EPU Index following the global financial crisis triggered by the bankruptcy of Lehman Brothers in

\footnotetext{
2 The selection of the rolling window size was based on a literature review (Aye, Balcilar, Dunne, Gupta, \& Eyden, 2014; Balcilar \& Ozdemir, 2013).
}

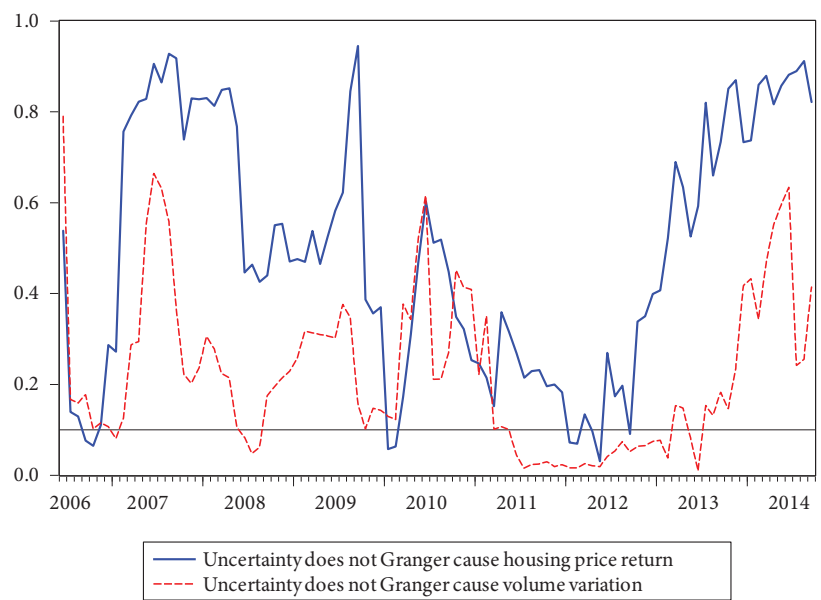

Figure 2. Bootstrap causality tests of uncertainty and trading variables

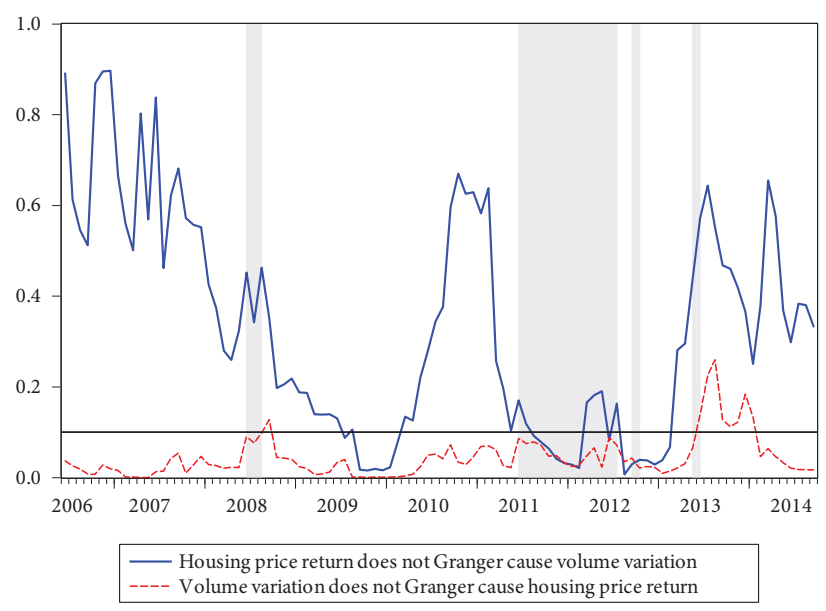

Figure 3. Bootstrap causality tests of price and volume

2008, and the increased default on European sovereign debt between 2011 and 2013. In the present study, we hypothesize that pessimistic market speculation reduces the information content of transaction volume. We then continue to analyze the causal PVR in the rolling window to validate the changes in transaction volume informativeness.

The dynamic causalities between housing price and transaction volume are illustrated in Figure 3. The solid line in Figure 3 denotes the significance level ( $p$ value) of which housing price return Granger-causes transaction volume, and the dotted line shows the significance level ( $p$ value) of which transaction volume Granger-causes housing price return. The shaded area of Figure 3 indicates the periods in which pessimistic market speculation reduces the information content of transaction volume (the periods in which the $p$-value was lower than 0.05 , as shown by the dotted line Figure 2). Figure 3 shows that the $p$-value is lower than 0.05 most of the time, indicating that volume leads price during most of the periods. However, the $p$-values in the shaded area exceed 0.05 and even 0.1 , implying that during these periods, volume does not lead price or possess the price discovery function. Figure 2 shows that between 2011 and 2012, housing price only briefly exhibits a significant lag in 
responding to market speculation. By contrast, transaction volume demonstrates a continuous information lag following June 2011, causing price to lead volume between 2011 and 2012 (as indicated by the $p$ values $<0.05$ in Figure 3).

The results illustrated in Figures 2 and 3 support the hypothesis proposed in the present study. Specifically, the informativeness of transaction volume decreases with the occurrence of pessimistic speculation, causing price to lead volume. The preceding discussion validates the effects of market conditions on the PVR and addresses how the PVR changes in the housing market.

In addition, another approach is employed to directly verify the market's negative impact on the informativeness of trading volume. A regime-switching model's endogenous estimation is adopted to evaluate whether different states exist in the relationship of volume lagging behind price, and if so, whether the change of state was a result of the market's negative impact. Table 7 contains the estimation results, which indicate that two states coexist regarding the relationship between the informativeness of trading volume and the price it reflects. In State 1 , the volume does not lag behind the price, whereas in State 2, the volume lags behind the price for four periods. Therefore, in State 1, volume-related informativeness is higher. Results of Table 7 also show that the possibility of State 1, namely high informativeness of the volume, is subject to whether the market has previously undergone

Table 7. Different information content of trading volume: regime-switching model

\begin{tabular}{|c|c|c|c|c|}
\hline \multicolumn{5}{|c|}{ Dependent variable: $\Delta \ln V$} \\
\hline Variable & Coefficient & $\begin{array}{l}\text { Std. } \\
\text { Error }\end{array}$ & $z$-Statistic & $p$-value \\
\hline \multicolumn{5}{|l|}{ Regime 1} \\
\hline$\Delta \ln H P I_{t-1}$ & 13.5346 & 21.4478 & 0.6310 & 0.5280 \\
\hline$\Delta \ln H P I_{t-2}$ & 21.8760 & 13.2439 & 1.6518 & 0.0986 \\
\hline$\Delta \ln H P I_{t-3}$ & -17.3745 & 21.1189 & -0.8227 & 0.4107 \\
\hline$\Delta \ln H P I_{t-4}$ & -23.5111 & 16.5024 & -1.4247 & 0.1542 \\
\hline Constant & -0.4528 & 0.1242 & -3.6448 & 0.0003 \\
\hline \multicolumn{5}{|l|}{ Regime 2} \\
\hline$\Delta \ln H P I_{t-1}$ & 0.9666 & 1.6341 & 0.5915 & 0.5542 \\
\hline$\Delta \ln H P I_{t-2}$ & 1.1146 & 1.9083 & 0.5841 & 0.5592 \\
\hline$\Delta \ln H P I_{t-3}$ & 0.4997 & 1.8953 & 0.2636 & 0.7921 \\
\hline$\Delta \ln H P I_{t-4}$ & -4.1972 & 1.5884 & -2.6424 & 0.0082 \\
\hline Constant & 0.0361 & 0.0122 & 2.9617 & 0.0031 \\
\hline \multicolumn{5}{|l|}{ Common } \\
\hline $\ln \sigma$ & -2.1814 & 0.0730 & -29.8707 & 0.0000 \\
\hline \multicolumn{5}{|c|}{ Probabilities parameters (probability of regime 1) } \\
\hline Constant & -2.7209 & 0.5365 & -5.0717 & 0.0000 \\
\hline$\triangle E P U_{t-1}$ & -3.1004 & 1.5277 & -2.0294 & 0.0424 \\
\hline
\end{tabular}

Notes: $\triangle \ln H P I$ is the growth rate of housing price index, $\Delta \ln V$ is the growth rate of trading volume. $\triangle E P U$ denotes the growth rate of economic policy uncertainty. $\sigma$ is the standard deviation. The optimal lag length of the estimated model was chosen by the Schwarz information criterion. negative impact; in other words, negative impact on the market reduces the possibility of high informativeness of volume and enhances the possibility of low informativeness. This result is consistent with those in Table 6, Figure 2 , and Figure 3. It also directly explains that the decrease in the informativeness of trading volume was because of negative impact on the market. In addition, Table 5 reveals that when uncertainty in the market increases, the trading volume only reacts to the impact four periods later; however, this phenomenon of lagging does not exist for price. Furthermore, the results in Table 7 confirm that the state change of informativeness caused by the market's negative impact reduces the informativeness of trading volume and leads the information to lag behind for four periods.

In addition, we hypothesize that transaction volume decreases concurrently with informativeness. To validate this hypothesis, the significant levels of which the increase in EPU Granger-causes transaction volume and the time sequence of transaction volume are illustrated in Figure 4 to conduct preliminary investigations. In Figure 4, the solid line represents the $p$-value corresponding to the values on the vertical axis to the left, and the dotted line represents transaction volume corresponding to the values on the vertical axis to the right. The results show a drastic drop in transaction volume in 2008 and between 2011 and 2012. Moreover, a delayed rebound in transaction volume (low transaction volume for over 12 months) and reduced transaction volume informativeness are observed, reflecting a lagging response to pessimistic speculation in the market.

A threshold regression (TR) model is developed to verify the effect of transaction volume size on the information content of transaction volume. We analyze the effect of transaction volume size on the PVR and examine the threshold value with the highest fit (Table 8). The results show that the PVR and the information content of transaction volume exhibited two conditions in accordance with high and low transaction volumes. The threshold value produced by the TR model is 54,461 ; therefore, a transaction volume below 54,461 indicates a market with low transaction activity (Condition 1), and a transaction volume over 54,461 indicates a market with high transaction activity (Condition 2). Among all sample periods in this study, 19 have low trading

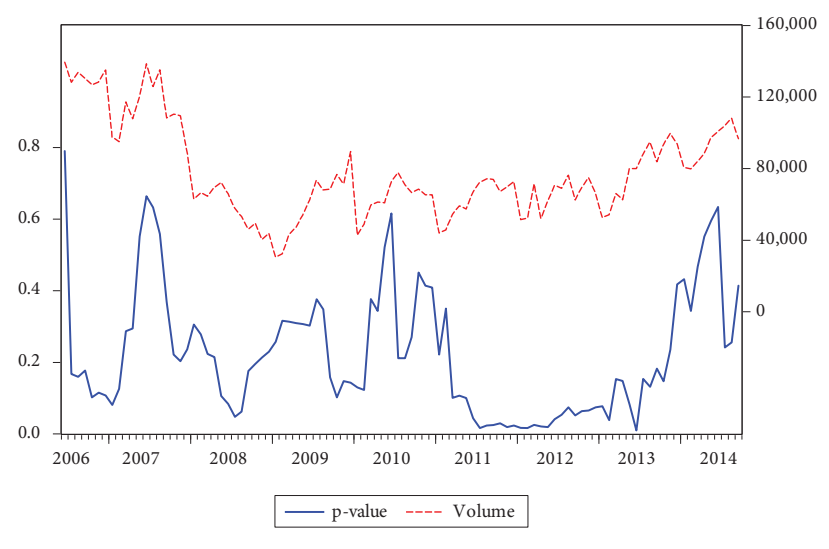

Figure 4. Trading volume and $p$-values 
Table 8. Different information content of trading volume: threshold regression

\begin{tabular}{|l|c|c|c|c|}
\hline \multicolumn{5}{|c|}{ Dependent variable: $\Delta \ln V$} \\
\hline Variable & Coefficient & $\begin{array}{c}\text { Std. } \\
\text { Error }\end{array}$ & $t$-Statistic & $p$-value \\
\hline$V<54461$ (19 obs) & -0.5537 & 0.1830 & -3.0256 & 0.0030 \\
\hline$\Delta \ln V_{t-1}$ & 0.4190 & 0.2814 & 1.4889 & 0.1391 \\
\hline$\Delta \ln V_{t-2}$ & 3.4567 & 5.9403 & 0.5819 & 0.5617 \\
\hline$\Delta \ln H P I_{t-1}$ & -14.1839 & 6.2180 & -2.2811 & 0.0243 \\
\hline$\Delta \ln H P I_{t-2}$ & -0.2449 & 0.0519 & -4.7219 & 0.0000 \\
\hline Constant & -0.1449 & 0.1236 & -1.1728 & 0.2431 \\
\hline$V \geq 54461(114$ obs) & -0.2609 & 0.1053 & -2.4771 & 0.0146 \\
\hline$\Delta \ln V_{t-1}$ & 2.9074 & 2.5267 & 1.1507 & 0.2521 \\
\hline$\Delta \ln V_{t-2}$ & 0.5011 & 2.2294 & 0.2248 & 0.8225 \\
\hline$\Delta \ln H P I_{t-1}$ & 0.0112 & 0.0172 & 0.6533 & 0.5148 \\
\hline$\Delta \ln H P I_{t-2}$ & & & \\
\hline Constant & & & \\
\hline
\end{tabular}

Notes: $\triangle \ln H P I$ is the growth rate of housing price index; $\Delta \ln V$ is the growth rate of trading volume. $V$ is the trading volume. The optimal lag length of the estimated model was chosen by the Schwarz information criterion.

volume and 114 have high trading volume; this reflects the fact that periods with low trading volume are those when the market exhibit unusual performance.

In Condition 1, transaction volume contains no pricerelated information content (price-leads-volume). When transaction volume falls below the threshold value of 54,461, the growth rate of transaction volume exhibits a significant and negative autocorrelation and is correlated with the negative growth of housing price lagging by two periods. Generally, housing prices and transaction volume are positively correlated. When transaction volume is restricted and reduced, it cannot reflect market information accurately. In Condition 2, transaction volume only exhibits an autocorrelation and is not affected by changes in housing prices in the lagging periods, suggesting that transaction volume is unrestricted and does not reflect lagging conditions.

The results discussed in this section verify that information lag occurs in transaction volume when volume drops to lower than $15 \%$ of that in the sample period.

\section{Conclusions}

The present study analyzes the PVR to verify the changes in the information content of housing transaction volume. A theoretical model is first developed to examine the housing market during the occurrence of pessimistic speculation. The results show that when trader behaviors are restricted (e.g., disposition effect or down payment restriction), transaction volume decreases, causing information lag.

The UK HPI and transaction volume data between January 2005 and March 2016, as well as the UK EPU Index, are used to determine whether pessimistic information is circulated in the housing market. The results reveal a long-term equilibrium PVR in the UK housing market, and that transaction volume is corrected once it shifts away from its longrun equilibrium with housing price. The "volume-leadsprice" situation is more evident in the short-term. In other words, the transaction volume of the UK housing market generally contains information content for price discovery.

We then consider the rise in market uncertainty to show that the housing price return remains unaffected by the rise in market uncertainty during the occurrence of pessimistic speculation. By contrast, transaction volume variation reflects pessimistic speculation four periods prior the current period, and that transaction volume decreases during pessimistic speculation. We adopt uncertainty as a proxy variable for representing pessimistic speculation and verify that transaction volume decreases during pessimistic speculation, becoming less informative.

To further verify the effects of pessimistic speculation on PVR trends, the rolling window bootstrap Granger causality test is performed, revealing that housing price return only lags in responding to pessimistic speculation in May 2012. By contrast, the lagging repsonse of transaction volume variation to pessimistic speculation is more evident. During 2008, 2011-2012, and 2013, transaction volume lags behind housing prices and loses its price discovery function. This verifies the hypothesis that the transaction volume loses informativeness during pessimistic speculation and that pessimistic speculation affects the causality between housing prices and transaction volume. The inconsistencies between the PVR findings of the present study and those of previous studies may be caused by different market conditions.

Finally, we employ model endogeneity to estimate the effect of transaction volume size on the informativeness of transaction volume. The results show that the information content of transaction volume is affected by transaction volume size. We determine that transaction volume variation lags behind housing price return when the volume drops to lower than $15 \%$ of that in the sample period. Moreover, we have not observed the positive correlation between housing prices and transaction volume, as reported in previous studies. This inconsitency might be attributed to how the market is restricted during pessimistic speculation, hindering the ability of transaction volume to reflect market information accurately. By contrast, transaction volume is informative when it is not restricted. The present study produces similar results as those reported by Andrew and Meen (2003), who also examine the UK housing market. In addition, the present study can explain the reduction in transaction volume and the inability of transaction volume to synchronously reflect price information in 1990 observed by Andrew and Meen (2003).

The present study contributes to research by collating and reviewing past studies concerning housing prices and transaction volume and by explaining changes in the informativeness of housing transaction volume and the causality between housing prices and transaction volume. This study also provides empirical evidence and formulates a simple method for determining the informativeness of transaction volume. 


\section{Acknowledgements}

I am immensely grateful to Professor Audrius Banaitis (Editor) and the two anonymous referees for the constructive comments of this paper. Funding from the Ministry of Science and Technology of Taiwan under Project No. MOST104-2410-H-390-028-MY3 has enabled the continuation of this research and the dissemination of these results.

\section{References}

Aastveit, K. A., Natvik, G. J., \& Sola, S. (2013). Economic uncertainty and the effectiveness of monetary policy. Norges Bank Working Paper. Retrieved from http://www.norges-bank.no/ en/Published/Papers/Working-Papers/2013/WP-201317/

Andrew, M., \& Meen, G. (2003). House price appreciation, transactions and structural change in the British housing market: a macroeconomic perspective. Real Estate Economics, 31(1), 99-116. https://doi.org/10.1111/j.1080-8620.2003.00059.x

Aye, G. C., Balcilar, M., Dunne, J. P., Gupta, R., \& Eyden, R. (2014). Military expenditure, economic growth and structural instability: a case study of South Africa. Defence and Peace Economics, 25(6), 619-633. https://doi.org/10.1080/10242694.2014.886432

Baker, S. R., Bloom, N., \& Davis, S. J. (2016). Measuring economic policy uncertainty. Quarterly Journal of Economics, 131(4), 1593-1636. https://doi.org/10.1093/qje/qjw024

Balcilar, M., \& Ozdemir, Z. A. (2013). The export-output growth nexus in Japan: a bootstrap rolling window approach. Empirical Economics, 44(2), 639-660. https://doi.org/10.1007/s00181-012-0562-8

Bansal, R. \& Yaron, A. (2004). Risks for the long run: a potential resolution of asset pricing puzzles. Journal of Finance, 59(4), 1481-1509. https://doi.org/10.1111/j.1540-6261.2004.00670.x

Bijsterbosch, M., \& Guérin, P. (2013). Characterizing very high uncertainty episodes. Economics Letters, 121(2), 239-243. https://doi.org/10.1016/j.econlet.2013.08.005

Case, K. E., \& Shiller, R. J. (1989). The efficiency of the market for single-family homes. American Economic Review, 79(1), 125-137.

Case, K. E., \& Shiller, R. J. (1990). Forecasting prices and excess returns in the housing market. Real Estate Economics, 18(3), 253-273. https://doi.org/10.1111/1540-6229.00521

Clark, P. (1973). A subordinated stochastic process model with finite variance for speculative process. Econometrica, 41, 135155. https://doi.org/10.2307/1913889

Clayton, J. (1998). Further evidence on real estate market efficiency. Journal of Real Estate Research, 15(1), 41-57.

Clayton, J., Miller, N., \& Peng, L. (2010). Price-volume correlation in the housing market: causality and co-movements. Journal of Real Estate Finance and Economics, 40(1), 14-40. https://doi.org/10.1007/s11146-008-9128-0

Copeland, T. (1976). A model of asset trading under the assumption of sequential information arrival. Journal of Finance, 41, 1149-1168. https://doi.org/10.2307/2326280

De Wit, E. R., Englund, P., \& Francke, M. K. (2013). Price and transaction volume in the Dutch housing market. Regional Science and Urban Economics, 43(2), 220-241. https://doi.org/10.1016/j.regsciurbeco.2012.07.002

Dzielinski, M. (2011). Measuring economic uncertainty and its impact on the stock market. Finance Research Letters, 9(3), 167-175. https://doi.org/10.1016/j.frl.2011.10.003

Eforn, B. (1979). Bootstrap methods: another look at the jackknife. Annals of Statistics, 7(1), 1-26. https://doi.org/10.1214/aos/1176344552

Engle, R. F. \& Granger, C. W. J. (1987). Co-integration and error correction: representation, estimation, and testing. Econometrica, 55(2), 251-276. https://doi.org/10.2307/1913236
Epps, T. \& Epps, M. (1976). The stochastic dependence of security price changes and transaction volumes: implication for the mixture of distribution hypothesis. International Review of Financial Analysis, 44, 305-321. https://doi.org/10.2307/1912726

Gallant, A., Rossi, P., \& Tauchen, G. (1992). Stock prices and volume. Review of Financial Studies, 5(2), 199-242. https://doi.org/10.1093/rfs/5.2.199

Genesove, D., \& Mayer, C. (2001). Loss aversion and seller behavior: evidence from the housing market. Quarterly Journal of Economics, 116(4), 1233-1260. https://doi.org/10.1162/003355301753265561

$\mathrm{Gu}, \mathrm{A}$. Y. (2002). The Predictability of house prices. Journal of Real Estate Research, 24(3), 213-233.

Hort, K. (2000). Prices and turnover in the market for owner-occupied homes. Regional Science and Urban Economics, 30(1), 99-119. https://doi.org/10.1016/S0166-0462(99)00028-9

Hoshi, T. (2011). Financial regulation: lessons from the recent financial crisis. Journal of Economic Perspectives, 49, 120-128. https://doi.org/10.1257/jel.49.1.120

Johansen, S. (1988). Statistical analysis of cointegration vectors. Journal of Economic Dynamics and Control, 12(2-3), 231-254. https://doi.org/10.1016/0165-1889(88)90041-3

Johansen, S., \& K. Juselius. (1990). Maximum likelihood estimation and inference on cointegration - with applications to the demand for money. Oxford Bulletin of Economics and Statistics, 52(2), 169210. https://doi.org/10.1111/j.1468-0084.1990.mp52002003.x

Johansen, S. (1991). Estimation and hypothesis testing of cointegration vectors in Gaussian vector autoregressive models. Econometrica, 59(6), 1551-1580. https://doi.org/10.2307/2938278

Kang, W., \& R. A. Ratti. (2013). Structural oil price shocks and policy uncertainty. Economic Modelling, 35, 314-319. https://doi.org/10.1016/j.econmod.2013.07.025

Karpoff, J. (1987). The relation between price changes and trading volume: a survey. Journal of Financial and Quantitative Analysis, 22, 109-126. https://doi.org/10.2307/2330874

Ko, J.-H., \& C.-M. Lee. (2015). International economic policy uncertainty and stock prices: wavelet approach. Economics Letters, 134(C), 118-122. https://doi.org/10.1016/j.econlet.2015.07.012

Leung, C., Lau, G., \& Leong, Y. (2002). Testing alternative theories of the property price-trading volume correlation. Journal of Real Estate Research, 23(3), 253-264.

Mantalos, P., \& Shukur, G. (1998). Size and power of the error correction model cointegration test: a bootstrap approach. Oxford Bulletin of Economics and Statistics, 60(2), 249-255. https://doi.org/10.1111/1468-0084.00097

Mantalos, P. (2000). A graphical investigation of the size and power of the granger-causality tests in integrated-cointegrated VAR systems. Studies in Nonlinear Dynamics \& Econometrics, 4(1), 1-18. https://doi.org/10.2202/1558-3708.1053

Miller, N. G., \& Sklarz, M. A. (1986). A note on leading indicators of housing price trends. Journal of Real Estate Research, 1(1), 99-109.

Shi, S., Young, M., \& Hargreaves, B. (2010). House price-volume dynamics: evidence from 12 cities in New Zealand. Journal of Real Estate Research, 32(1), 75-99.

Stein, J. C. (1995). Prices and trading volume in the housing market: a model with down-payment effects. Quarterly Journal of Economics, 110(2), 379-406. https://doi.org/10.2307/2118444

Tsai, I-C. (2014). Ripple effect in house prices and trading volume in the UK housing market: new viewpoint and evidence. Economic Modelling, 40(C), 68-75. https://doi.org/10.1016/j.econmod.2014.03.026

Zhou, Z.-G. (1997). Forecasting sales and price for existing single-family homes: a VAR model with error correction. Journal of Real Estate Research, 14(2), 155-167. 